\title{
OBSTRUCCIÓN CRÓNICA DE LA VÍA AÉREA EN LA INFANCIA. CAUSAS MÁS FRECUENTES, DIAGNÓSTICO Y TRATAMIENTO QUIRÚRGICO Y ENDOSCÓPICO
}

\section{Chronic airway obstruction in children. Most common causes, diagnosis and Surgical and Endoscopic Treatment}

\author{
Ana Isabel NAVAZO-EGUÍA'; Juan L. ANTÓN-PACHECO-SÁNCHEZ² \\ ${ }^{1}$ Servicio de Otorrinolaringología. Hospital Universitario de Burgos. España ${ }^{2}$. Servicio de Cirugía Pediátrica. Hospital \\ Universitario Doce de Octubre. Madrid. España \\ Correspondencia: navazoeguia@gmail.com
}

Fecha de recepción: 21 de marzo de 2017

Fecha de aceptación: 9 de junio de 2017

Fecha de publicación: 15 de julio de 2017

Fecha de publicación del fascículo: 1 de marzo de 2018

Conflicto de intereses: Los autores declaran no tener conflictos de intereses

Imágenes: Los autores declaran haber obtenido las imágenes con el permiso de los pacientes Política de derechos y autoarchivo: se permite el autoarchivo de la versión post-print (SHERPA/RoMEO) Licencia CC BY-NC-ND. Licencia Creative Commons Atribución-NoComercial-SinDerivar 4.0 Internacional Universidad de Salamanca. Su comercialización está sujeta al permiso del editor

RESUMEN

Introducción: La patología obstructiva de la vía aérea en la infancia incluye lesiones congénitas y adquiridas. Afortunadamente, es poco frecuente, pero plantea en la mayoría de los casos un desafío diagnóstico y terapéutico. Las técnicas endoscópicas han experimentado un gran avance en el tratamiento de estas lesiones, pero la cirugía abierta sigue teniendo un importante papel. Objetivo: Nuestro objetivo ha sido revisar las causas más frecuentes de obstrucción de la vía aérea central en el niño, su manejo diagnóstico y situación actual del tratamiento. Conclusiones: La patología obstructiva de la vía aérea en el niño requiere estabilización inmediata, evaluación detallada, planificación meticulosa y tratamiento individualizado. La cirugía de la vía aérea requiere de especialistas organizados en equipos multidisciplinarios cuyo objetivo principal es el diagnóstico y la resolución oportuna de las diversas malformaciones congénitas y lesiones adquiridas que afectan la laringe, tráquea y bronquios. En muchas ocasiones la decisión del tratamiento de elección no es fácil. La selección de la mejor opción quirúrgica se debe basar en las condiciones locales y generales del paciente. El cirujano debe dominar todas las técnicas disponibles, para resolver cada situación específica.

PALABRAS CLAVE estridor; estenosis laringotraqueales; reconstrucción laringotraqueal; broncoscopia diagnóstica y terapéutica

SUMMARY

Introduction: Obstructive airway pathology in children may be congenital or acquired. Fortunately, it is a rare condition, but in most cases, it implies a diagnostic and therapeutic challenge. Endoscopic techniques have experienced in the last years a breakthrough in the treatment of 
these lesions, but open surgery still plays an important role. Objective: Our objective was to review the most frequent causes of obstruction of the central airway in the child, their diagnostic and current treatment status. Conclusions: Obstructive airway pathology in children requires immediate stabilization, detailed assessment, meticulous planning and individualized treatment. Management of patients with airway obstruction requires a close cooperation between specialists organized in multidisciplinary teams, whose main objective is the diagnosis and timely resolution of the various congenital malformations and acquired lesions that affect the larynx, trachea and bronchi. In many cases the decision of the treatment of choice is not easy. Selection of the most suitable treatment depends on the patient's clinical situation and the anatomic type of stenosis. The surgeon must master all available techniques, to solve each specific situation.

\section{INTRODUCCIÓN}

Las enfermedades obstructivas que afectan la laringe y tráquea se clasifican de acuerdo a su naturaleza en congénitas y adquiridas. La incidencia de esta patología en la infancia afortunadamente no es frecuente y generalmente es causada por lesiones no malignas. La malacia y las estenosis congénitas o adquiridas son las más frecuentes.

Las anomalías congénitas de la vía aérea representan más del $85 \%$ de los casos de los niños remitidos para evaluación por estridor crónico y síntomas respiratorios en el periodo neonatal y lactancia [1].

Por otra parte, las anomalías adquiridas parecen estar aumentando a causa del avance en las técnicas de diagnóstico y tratamiento (intubaciones prolongadas, aspiraciones, etc.) que permiten una supervivencia mayor en patologías antes letales, como los recién nacidos pretérmino de bajo peso y ciertas cardiopatías. En todos los casos, el estridor en los niños significa una obstrucción de las vías respiratorias que supone una amenaza vital en potencia. Solo podemos considerarlo benigno una vez que hayamos explorado la vía aérea. Debe estudiarse y diagnosticarse precozmente para evitar complicaciones derivadas de la hipoxia [2].

Los estudios diagnósticos más frecuentemente utilizados son la tomografía axial computarizada (TAC) y la endoscopia [3]. Con la TAC se adquieren cortes axiales que permiten hacer reconstrucciones en 3 dimensiones, de gran utilidad en el diagnóstico, planificación de procedimientos y seguimiento de estos pacientes. Tanto la endoscopia flexible como la rígida facilitan una visión directa de la lesión, permitiendo evaluar la presencia y el grado de estrechamiento de la luz, el estado de la mucosa, la longitud, la forma, y la distancia de la estenosis con respecto a las cuerdas vocales y a la carina principal. Además, permiten la toma de muestras para cultivo microbiológico, estudio citológico y anatomopatológico.

\section{MATERIAL Y MÉTODO}

Hemos realizado una revisión de las causas más frecuentes de la patología obstructiva benigna de la vía aérea infantil, su manejo diagnóstico y situación actual del tratamiento.

\section{ESTENOSIS LARINGOTRAQUEALES}

Las estenosis laringotraqueales en la infancia pueden ser congénitas o adquiridas. Se describen dos tipos principales, las estenosis estructurales o fijas y las estenosis dinámicas, que se refieren a malacia cuyas condiciones varían con la respiración [4].

Frente a lo que sucede en los adultos, la obstrucción de la vía respiratoria debida a tumores malignos es rara en la infancia. Las malacias 0 las estenosis benignas son las causas más frecuentes.

El abordaje de las estenosis varía dependiendo de la presentación clínica, la localización de la lesión, la gravedad y el tipo de estenosis, el mecanismo por el que se haya producido y la presencia de comorbilidades. Todas estas variables, junto con la experiencia del cirujano y el endoscopista, determinarán la opción terapéutica más adecuada.

Su manejo es un reto que involucra diversas estrategias, que deben ser individualizadas para cada paciente, para lo que se requiere una evaluación preoperatoria precisa para seleccionar la mejor opción quirúrgica y que proporcione una información sobre factores que van a tener una influencia potencialmente decisiva en el resultado postoperatorio.

En 2015 se publicó el documento de consenso de la European Laryngological Society [5], con 
el objetivo de proponer un sistema de evaluación fácilmente utilizable para los cirujanos que manejan estenosis laringotraqueales.

En primer lugar, es importante distinguir entre la estenosis incipiente y la estenosis cicatricial madura. La estenosis incipiente se debe generalmente al estrechamiento agudo o subagudo de la vía aérea, generalmente tras intubación, debido a edema, ulceraciones o tejido de granulación, el propósito del tratamiento, generalmente endoscópico, es evitar la traqueotomía o permitir la decanulación en el caso de traqueotomizados.

En el caso de estenosis cicatriciales maduras, es de suma importancia comprender las características individuales de la estenosis y el contexto clínico de cada paciente mediante la valoración endoscópica preoperatoria.

El comité de la European Laryngological Society sugiere que la evaluación preoperatoria debería consistir en una combinación de varias modalidades endoscópicas [5]:

1- Fibroendoscopia transnasal. En pacientes adultos, puede realizarse fácilmente, pero en los niños no colaboradores es necesario realizar la exploración bajo anestesia general y respiración espontánea. El fibroendoscopio se introduce a través de una pequeña abertura en la máscara facial (Figura 1). La inspección de las cavidades nasales en ambos lados permite la identificación de cualquier patología, como la estenosis vestibular, estenosis de apertura piriforme, tabique desviado o hipertrofia de cornetes. Debe prestarse especial atención a identificar los estrechamientos anatómicos o funcionales en las coanas o nasofaringe (atresia coanal e hiperplasia adenoidea). En caso de apnea obstructiva del sueño se identificará el nivel exacto de obstrucción (retroposición del paladar, hiperplasia de las amígdalas y de la base de la lengua, laringomalacia, quiste o masa vallecular, epiglótica y supraglótica). Este examen proporciona además información sobre la movilidad normal de cuerdas vocales, restricción de la abducción unilateral o bilateral de las cuerdas vocales a menudo vinculada a la estenosis de la glotis posterior, y parálisis unilateral o bilateral de las cuerdas vocales de origen neurogénico o por fijación de la articulación cricoaritenoidea. Posteriormente se realiza el examen dinámico de la tráquea y bronquios durante la inspiración, expiración y tos, indispensable para el diagnóstico de traqueo o broncomalacia localizada o difusa. Se identificarán otros estrechamientos anatómicos de la vía aérea inferior.

2- Laringotraqueoscopia transoral directa con endoscopio de cero grados. En el paciente completamente relajado y con nebulización de la vía aérea con anestésicos locales, se introduce el endoscopio con ayuda del laringoscopio anestésico (Mclntosh) o mejor mediante microlaringoscopia de suspensión. En los adultos, esta evaluación puede hacerse con el endoscopio de $8 \mathrm{~mm}$, mientras que en el grupo de edad pediátrica con el endoscopio de $4 \mathrm{~mm}$. Si el diámetro de 4 $\mathrm{mm}$ es demasiado grande, entonces un telescopio de 2,7 mm o 1,9 mm Se identificará de manera precisa el sitio, el grado y la extensión cráneo-caudal de la estenosis, así como su relación y distancia al traqueostoma cuando está presente. El grado de estenosis se valora pasando endoscopios, bugías o tubos endotraqueales de diferentes tamaños a través de la estenosis.

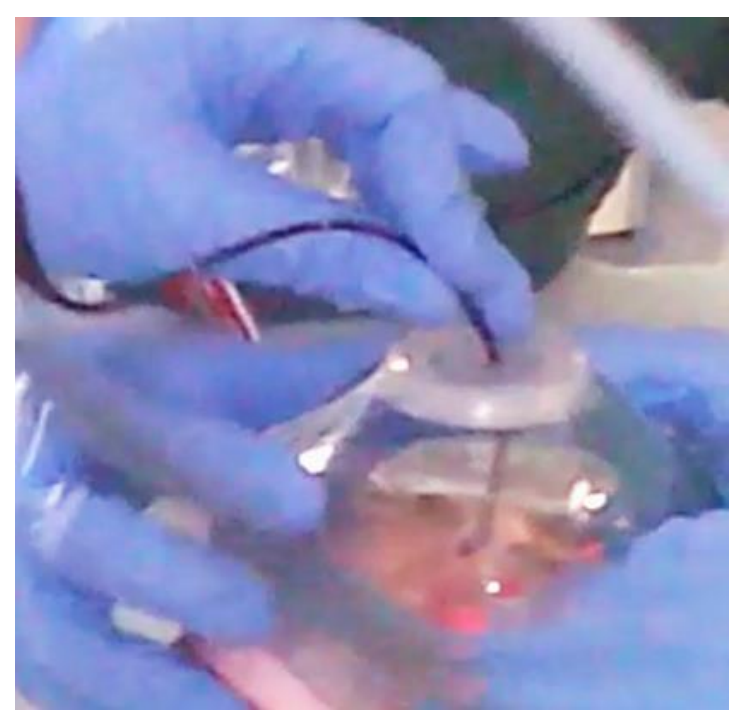

Figura 1. Obstrucción crónica de la vía aérea en la infancia. Fibroendoscopia transnasal a través de la máscara facial.

CAusas más fRECUENTES DE Estenosis LARINGOTRAQUEAL.

1. Laringomalacia. La laringomalacia es la anomalía laríngea congénita más frecuente y la causa más habitual de estridor en la infancia (60-75\%). Se define por el colapso intraluminal 
de los tejidos supraglóticos durante la inspiración. La causa es desconocida. Se postulan tres factores que pueden influir en su génesis [6]:

- Anatómicos. Se han descrito principalmente tres tipos de anomalías anatómicas en la supraglotis: epiglotis enrollada en omega, ligamentos aritenoepiglóticos cortos y aritenoides abultados redundantes. Estos tipos de lesiones se pueden encontrar en forma combinada o aislada.

- Histológicos. Se ha sugerido que la inmadurez de los cartílagos laríngeos daría lugar a una debilidad intrínseca y tendencia al colapso durante la inspiración.

- Neuromusculares. La inmadurez en el control neuromuscular se ha descrito como otra posible causa. Pudiendo ser la manifestación de una hipotonía.

Clínicamente se manifiesta como un estridor inspiratorio progresivo, generalmente intermitente, aunque también puede ser constante. Su intensidad aumenta con el decúbito supino, mejorando al decúbito prono, y empeora con los esfuerzos del niño, ya sea con el llanto, al agitarse o al mamar. Su sintomatología es máxima a los 6 meses de vida. Habitualmente, se resuelve antes de los 18-24 meses.

Los casos graves, pueden presentar aspiración, cianosis, apneas obstructivas, accesos de tos, bronquitis de repetición y pectus excavatum. Durante el sueño puede desencadenar crisis de apnea que se han relacionado con la muerte súbita del lactante.

El diagnóstico se realiza mediante la rinofibrolaringoscopia flexible. Se deberá completar el estudio de toda la vía aérea en los casos que no evolucionan bien o los de mayor severidad, por la posibilidad de otras anomalías asociadas. Se describen dos tipos fundamentales de anomalías:

- Epiglosis flácida con plicatura axial inspiratoria (laringomalacia anterior).

- Basculación anterior de los aritenoides en inspiración (laringomalacia posterior).

Otros autores la clasifican según el hallazgo endoscópico más frecuente en [7] (Figura 2):

Tipo 1: prolapso de la mucosa redundante de los aritenoides.

Tipo 2: repliegues ariepiglóticos acortados.

Tipo 3: posterior desplazamiento de la epiglotis.
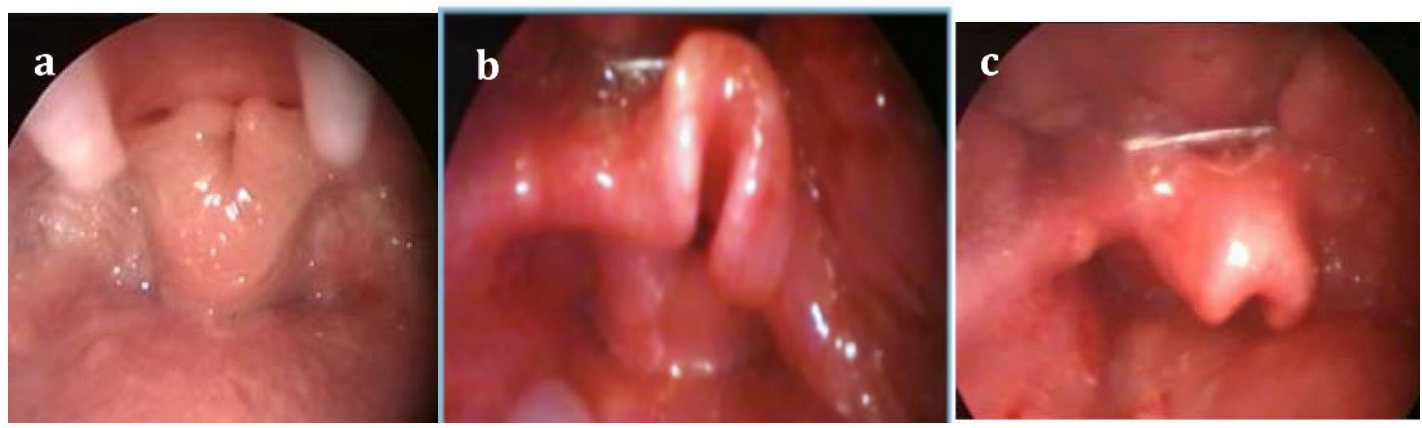

Figura 2. Obstrucción crónica de la vía aérea en la infancia. Tipo de laringomalacia según hallazgos endoscópicos: a: tipo I, b: tipo 2, c: tipo 3.

\section{PARÁLISIS DE CUERDAS VOCALES}

La mayoría de los casos evolucionan de manera benigna y sólo requieren una actitud expectante, pero el 5 al $25 \%$ presentan una enfermedad severa que puede requerir un tratamiento activo quirúrgico mediante técnicas endoscópicas ya sea mediante láser $\mathrm{CO} 2$ o con microinstrumental (supraglotoplastia) con sección de uno o ambos repliegues ariepiglóticos, sección parcial de los bordes laterales de la epiglotis y vaporización de mucosa de cartílagos corniculados y borde libre de la epiglotis [7].

La ventilación no invasiva (CPAP/BPAP) permite evitar la traqueotomía en los casos graves, los que no responden a la cirugía, con comorbilidades asociadas, en espera de una evolución favorable o de la realización del tratamiento quirúrgico.

La parálisis de cuerdas vocales es, según la literatura, la segunda causa más importante de 
estridor crónico infantil [8]. Puede ser congénita $o$ adquirida.

La parálisis congénita se manifiesta en el primer mes de vida, en los casos bilaterales con estridor, cianosis y apnea y en los casos unilaterales con disfonía. Ambos casos pueden presentar dificultades a la deglución y retracción esternal.

La parálisis unilateral, es consecuencia generalmente de maniobras de extracción durante el parto (fórceps, presentación de nalgas) o cirugía cardiaca previa (cierre de ductus arterioso, reparación de coartación de aorta), de mediastino (reparación de fístula traqueoesofágica) o de cuello donde puede dañarse el nervio recurrente laríngeo [9].

Las bilaterales, la mayoría de veces, se asocian a una enfermedad neurológica (ArnoldChiari, hidrocéfalo, mielomeningocele, agenesias cerebrales, disgenesias nucleares, hipotonías mayores, sufrimiento por anoxia cerebral); en otras ocasiones, son idiopáticas, y en ocasiones, se asocian a una estenosis subglótica [9].

Antes de iniciar el tratamiento se debe tener en cuenta que las posibilidades de recuperación espontánea son del orden del $60-70 \%$ durante el primer año.

La parálisis unilateral se debe tratar de forma expectante. En la parálisis bilateral, si existe disnea obstructiva grave, se debe proceder a la intubación oro o nasotraqueal. Si en tres semanas no se ha podido efectuar la extubación se procederá a realizar una traqueostomía. En caso de que durante el primer año de vida el niño no muestra signos de recuperación espontánea se debe proponer un tratamiento quirúrgico definitivo.
Se han descrito, para su tratamiento (Figura 3), diferentes técnicas endoscópicas (cordotomía posterior, o aritenoidectomia) o técnicas abiertas (aritenopexia o interposición de injertos) [9].

\section{ESTENOSIS SUBGLÓTICA}

La estenosis subglótica congénita es un cuadro poco frecuente representando menos del $10 \%$ de las causas de estridor en el lactante y recién nacido. Esta alteración se puede presentar de forma aislada o asociada a otros síndromes malformativos.

La estenosis subglótica más frecuente es la de etiología adquirida por intubación oro o nasotraqueal. El espacio subglótico es la porción más estrecha y la única rodeada por un anillo cartilaginoso completo. Su diámetro estrecho, la inextensibilidad de los tejidos circundantes, la fragilidad del tejido de revestimiento y la pobre vascularización, la hacen más susceptible al trauma por intubación.

La clínica, fundamentalmente, dependerá de la edad y del grado de estenosis. La estenosis grave, da lugar a estridor inspiratorio y espiratorio, disnea, cianosis, que en los casos más severos conduce a la muerte. La presentación más frecuente, en las formas más leves, es como episodios de laringitis subglótica o de croup recurrentes. En estos casos, se debe tener la sospecha clínica y llevar a cabo una fibrolaringoscopia.

Cotton-Myer [10], establecieron un sistema de clasificación: Grado I corresponde a menos del $50 \%$ de obstrucción de las vías respiratorias; Grado II a 51-70\%; Grado III hasta 71-99\%; Grado IV con luz no detectable (Figura 4).
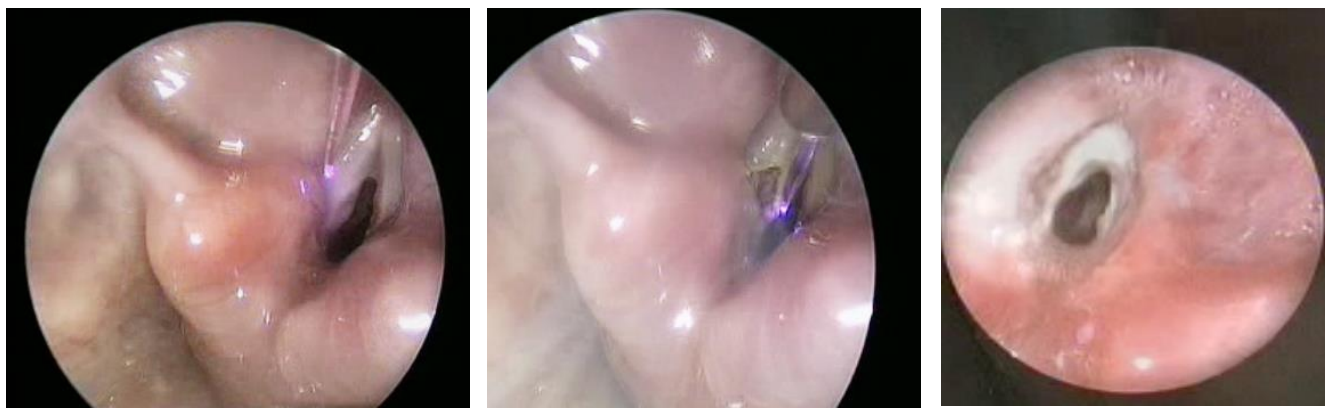

Figura 3. Obstrucción crónica de la vía aérea en la infancia. Tratamiento de las parálisis de cuerdas vocales. Cordotomía posterior láser. 


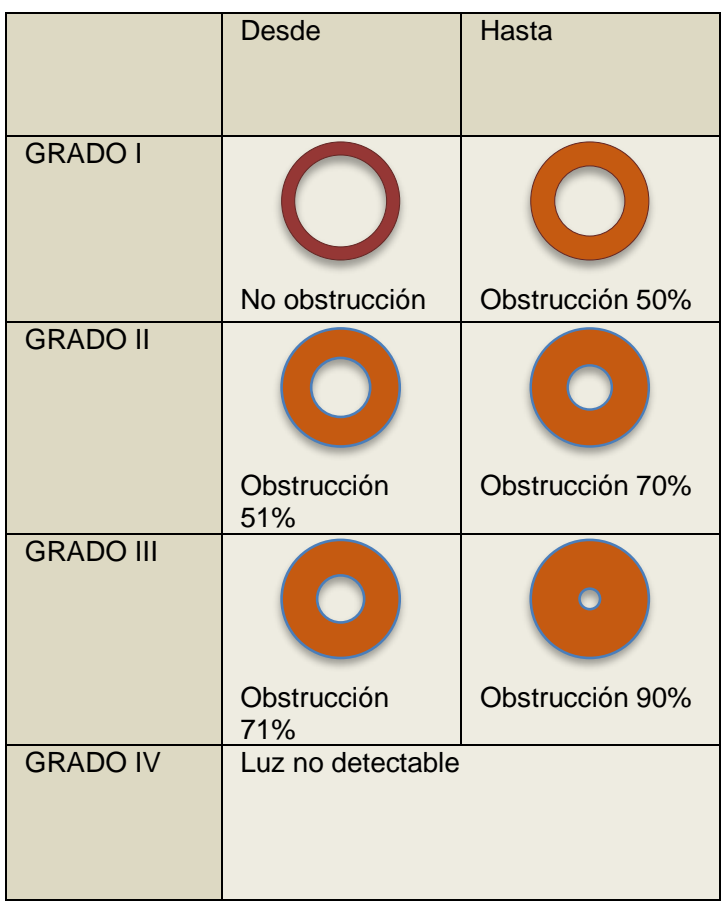

Figura 4. Obstrucción crónica de la vía aérea en la infancia. Clasificación de la estenosis subglótica de CottonMyer [10]

Actualmente se propone una nueva clasificación simple y fácil de recordar (Tabla 1), basada en el Cotton-Myer, que incorpora tres parámetros adicionales que van a influir en la técnica quirúrgica de elección más adecuada para cada caso: comorbilidades, compromiso glótico y la asociación de ambos [11].

Tabla 1. Obstrucción crónica de la vía aérea en la infancia. Clasificación de las estenosis subglóticas [11].

\begin{tabular}{|l|l|l|l|l|}
\hline $\begin{array}{l}\text { Grado } \\
\text { Cotton- } \\
\text { Myer }\end{array}$ & $\begin{array}{l}\text { ESG } \\
\text { aislada }\end{array}$ & $\begin{array}{l}\text { ESG+ } \\
\text { CM }\end{array}$ & $\begin{array}{l}\text { ESG+ } \\
\text { AG }\end{array}$ & $\begin{array}{l}\text { ESG+AG+ } \\
\text { CM }\end{array}$ \\
\hline $\begin{array}{l}\text { I } \\
0-50 \%\end{array}$ & I a & I b & I c & I d \\
\hline $\begin{array}{l}\text { II } \\
51-70 \%\end{array}$ & II a & II b & II c & II d \\
\hline $\begin{array}{l}\text { III } \\
71-99 \%\end{array}$ & III a & III b & III c & III d \\
\hline $\begin{array}{l}\text { IV } \\
\text { Sin luz }\end{array}$ & IV a & IV b & IV c & IV d \\
\hline
\end{tabular}

ESG: Estenosis subglótica. CM: comorbilidades. AG: Afectación glótica

Las comorbilidades incluyen prematuridad severa, enfermedad de membrana hialina, insuficiencia respiratoria, anomalías cardíacas, enfermedades neurológicas, reflujo gastroesofágico, obstrucción de la vía aérea extralaríngea, así como las anomalías congénitas sindrómicas o no sindrómicas.

La afectación glótica incluye estenosis glótica posterior, fusión de las cuerdas vocales o parálisis o fijación uni o bilateral de las cuerdas vocales.

El tratamiento de la estenosis subglótica debe adaptarse a cada situación individual. En pacientes asintomáticos o con síntomas moderados se aconseja seguir una actitud conservadora. En los casos graves se requiere tratamiento quirúrgico $[12,13]$.

En ciertos casos, la cirugía puede no ser factible por lo que debe evitarse. Un ejemplo de esta situación es el tratamiento de un niño con estenosis glotosubglótica, retraso mental y falta de coordinación faringo-laríngea. En este caso, la reconstrucción quirúrgica no aportará ninguna posibilidad de mejora.

La estenosis subglótica congénita no es generalmente susceptible de tratamiento láser primario pues la estenosis suele ser de naturaleza cartilaginosa. El tratamiento con láser de dióxido de carbono (CO2) combinada con la dilatación con balones y aplicación de mitomicina puede ser eficaz en el tratamiento de estenosis subglóticas diafragmáticas de consistencia blanda, membranosas, con adecuado soporte cartilaginoso, con longitudes en torno al centímetro, no concéntricas, que correspondan a los grados I y II de Cotton-Myer (Figura 5), siempre que la estenosis no implique la pared, especialmente a nivel de la tráquea membranosa (Figura 6) [14].

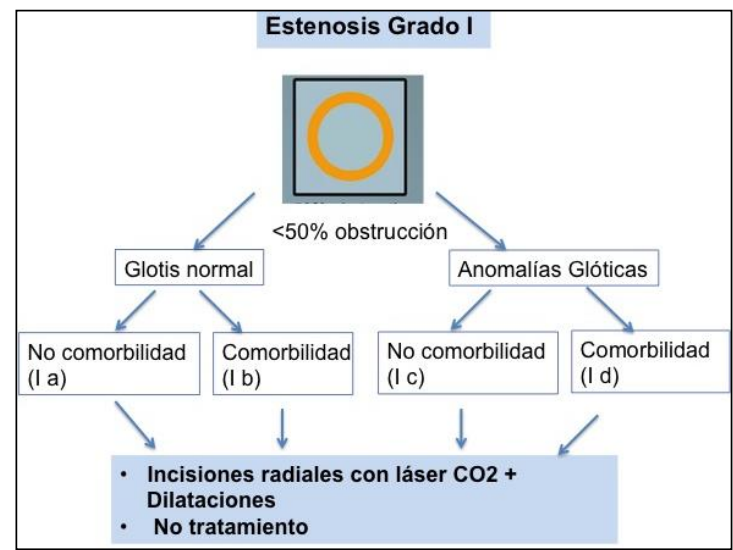

Figura 5. Obstrucción crónica de la vía aérea en la infancia. Tratamiento de las estenosis Grado I.

Adaptado de Philippe Monnier. Pediatric Airway Surgery. Management of Laryngotracheal Stenosis in Infants and Children. Surgery for Laryngotracheal Stenosis. Springer Heidelberg Dordrecht (London New York) 2011. p. 231-79. 


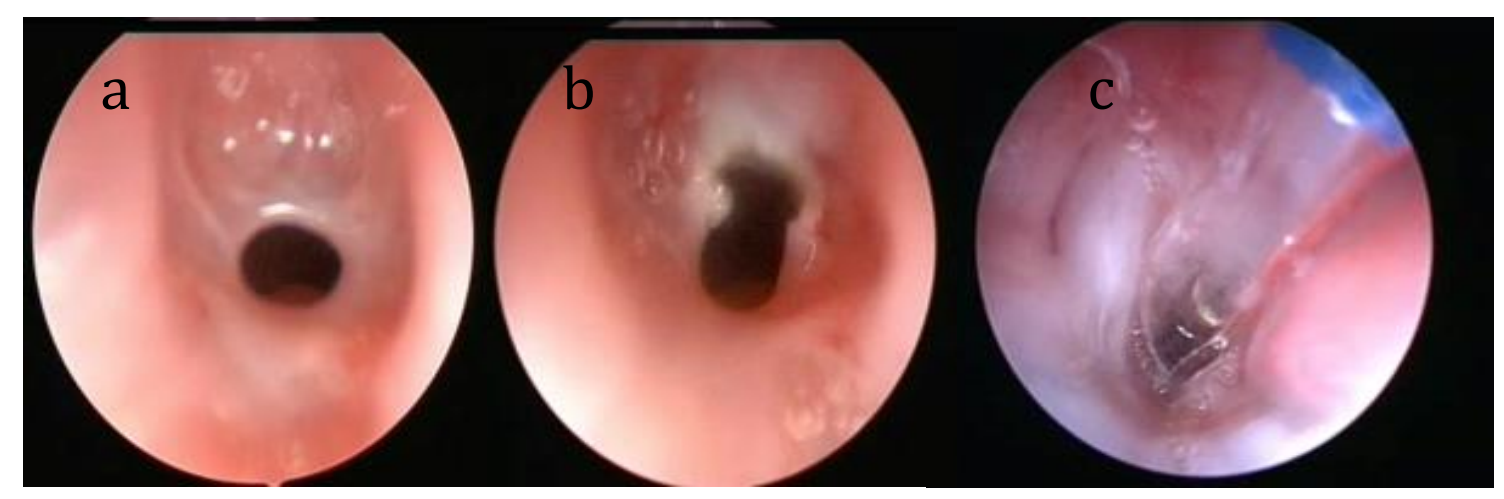

Figura 6 Tratamiento endoscópico de la estenosis subglótica. a: estenosis subglótica grado II, b: resección endoscópica con láser $\mathrm{CO} 2$, c: dilatación con balón.

La reconstrucción laringotraqueal con injerto anterior se utiliza para la resolución de la estenosis grado II. En el caso de estenosis grado III leves, se utiliza un injerto anterior con una fractura posterior del cricoides apoyada por un stent endoluminal (Figura 7), mientras que el grado III severo requiere tanto injertos anteriores como posteriores con stent [15].

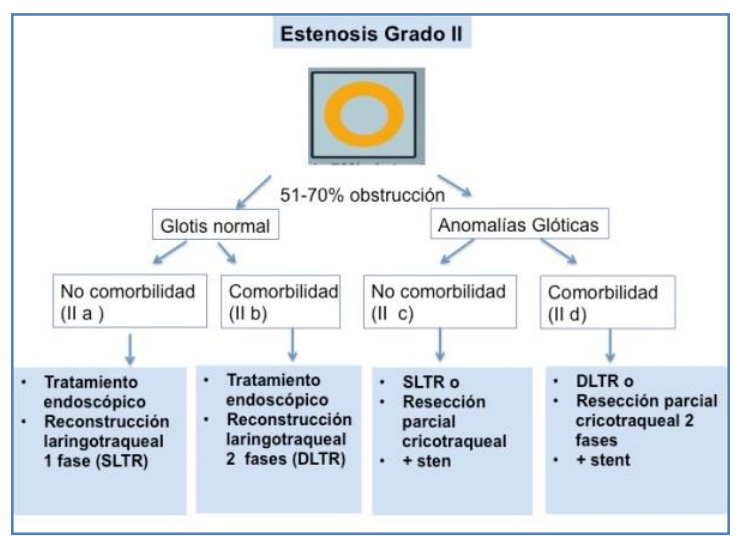

Figura 7. Obstrucción crónica de la vía aérea en la infancia Tratamiento de la estenosis subglótica grado II. Adaptado de Philippe Monnier. Pediatric Airway Surgery. Management of Laryngotracheal Stenosis in Infants and Children. Surgery for Laryngotracheal Stenosis. Springer Heidelberg Dordrecht (London New York) 2011. p. 231-79. SLTR: Reconstrucción laringotraqueal en un tiempo. DLTR: Reconstrucción laringotraqueal en dos tiempos.

En la última década, la resección parcial cricotraqueal ha surgido como una alternativa superior para el tratamiento de los grados III y IV de estenosis subglótica [16-18]. En en una sola etapa (con resección del traqueostoma durante la cirugía) cuando la estenosis es puramente subglótica y sin comorbilidades asociadas. En los casos donde el traqueostoma es muy distal ( $5^{\circ} \circ 6^{\circ}$ anillo traqueal) 0 en aquellos niños con múltiples anomalías congénitas, alteraciones neurológicas, cardíacas o pulmonares, se realizará en dos etapas (con mantenimiento postoperatorio del traqueostoma).

Si la estenosis subglótica se combina con compromiso glótico (estenosis gótica posterior, fusión cicatricial de las cuerdas vocales) o cuando la estructura laríngea esta distorsionada debido a intentos quirúrgicos anteriores fallidos, se aconseja (Figura 8) la resección parcial cricotraqueal con injertos de cartílago costal anterior y posterior y stent postoperatorio (unas tres semanas, hasta que se obtenga la cicatrización completa subglótica), con cierre del traqueostoma en un segundo tiempo quirúrgico [19].

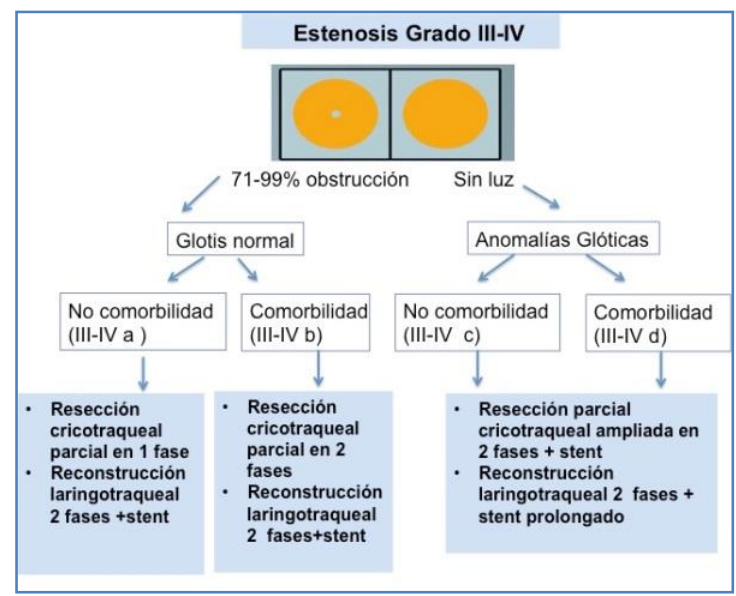

Figura 8. Obstrucción crónica de la vía aérea en la infancia Tratamiento de la estenosis subglótica grado III.

Adaptado de Philippe Monnier. Pediatric Airway Surgery. Management of Laryngotracheal Stenosis in Infants and Children. Surgery for Laryngotracheal Stenosis. Springer Heidelberg Dordrecht (London New York) 2011. p. 231-79. 


\section{MEMBRANAS LARÍNGEAS}

Las membranas laríngeas congénitas son poco frecuentes (menos de $5 \%$ ). Se originan por un fallo de recanalización de la laringe primitiva entre la octava y décima semana de desarrollo embriológico (20). De hecho, comparten la misma patogénesis que la estenosis subglótica congénita y puede considerarse un subgrupo de esta entidad. En algunos casos se asocian con microdelección de cromosoma 22q11 (síndrome velocardiofacial) [21].

Se clasifican según Cohen [22] en cuatro grados de gravedad:

- Tipo I: membrana anterior que afecta $<35 \%$ de la longitud de la glotis.

- Tipo Il: membrana que afecta entre 35\% al 50\% de la longitud de la glotis.

- Tipo III: membrana gruesa con potencial afectación subglótica cartilaginosa que afecta entre $50-75 \%$ de la longitud glótica.

- Tipo IV: afectación entre el $75 \%$ al $90 \%$ de la longitud glótica con estenosis subglótica cartilaginosa asociada.

Los síntomas dependen en gran medida de la extensión de la membrana desde disfonía leve a la afonía y desde ausencia de disnea hasta disnea severa obstructiva. Sin una traqueotomía de emergencia o un procedimiento EXIT, la atresia completa es incompatible con vida.

El diagnóstico se basa fundamentalmente en la fibrolaringoscopia que permite además evaluar la movilidad de las cuerdas vocales y la laringoscopia rígida que define el grado, extensión de la membrana y la posible afectación subglótica.

La TAC permite evaluar la extensión craneocaudal de la membrana.

El tratamiento se basa en la gravedad [23, 24]:

- Tipo I: observación o división de la membrana con láser $\mathrm{CO} 2$ con colgajos mucosos.

- Tipo Il: división láser de CO2 y colocación endoscópica de una quilla de silicona en la comisura anterior.

- Tipo III: división láser de CO2 con quilla endoscópica o cirugía abierta en caso de componente cartilaginoso.

- Tipo IV: traqueotomía; resección cricotraqueal parcial o reconstrucción laringotraqueal con tutor temporal.

\section{HEMANGIOMAS SUBGLÓTICOS}

Los hemangiomas son los tumores de cabeza y cuello más frecuentes en la infancia [23]. El hemangioma subglótico es raro, representa el 1,5\% de las anomalías congénitas laríngeas, y puede comprometer la vía aérea. Coincide con hemangiomas cutáneos en el $50 \%$ de los casos. Se presentan con más frecuencia en niñas (2:1), prematuros y recién nacidos de bajo peso. El síntoma de presentación es el estridor bifásico que empeora con la agitación, el llanto o las infecciones respiratorias.

El diagnóstico se realiza mediante la visualización de una masa submucosa, rosada o púrpura en la subglotis. No se recomienda la realización de biopsia debido al alto riesgo de sangrado.

La historia natural de los hemangiomas es de un crecimiento importante durante los primeros meses de vida y una involución lenta y espontánea a partir de los doce meses de vida. Se han descrito numerosas modalidades de tratamiento como los corticoides, interferón, cirugía, y recientemente el propranolol.

El propranolol ha desplazado a los corticoides y a la cirugía como primera línea de tratamiento (Figura 9). Tiene como ventajas su rápida respuesta, escasos efectos secundarios y bajo coste [25].

\section{QUISTES FARINGOLARÍNGEOS CONGÉNITOS}

Los quistes faringolaríngeos congénitos son poco frecuentes $[23,26]$.

Los quistes ductales son los más frecuentes. Resultan de la retención de moco debido a la obstrucción de una glándula mucosa. Dependiendo de su localización (subglótica o faringolaríngea) pueden provocar obstrucción de la vía aérea superior.

Los quistes saculares y laringoceles son menos frecuentes. Ambos resultan de una dilatación anormal o hernia del sáculo laríngeo, que está lleno de moco en el caso de los quistes saculares y con aire en el caso de laringoceles. La disnea acompañada de estridor inspiratorio, que puede mejorar con la extensión de la cabeza, puede estar presente al nacimiento o posteriormente en los primeros meses si aumentan su tamaño, especialmente con infecciones del tracto aéreo.

En la fibrolaringoscopia se observa una masa quística, con una pared mucosa de color amarillento, a nivel lateral, si es un quiste de ventrículo, o a nivel anterior, si es un quiste de vallécula. 
Los quistes laríngeos congénitos se deben tratar siempre por su potencial riesgo de crecimiento. El tratamiento consiste en la exéresis del quiste a través de la laringoscopia directa.
Si esta no es posible, se puede llevar a cabo una marsupialización endoscópica de la lesión o exéresis a través de una cervicotomía lateral [26, 27].

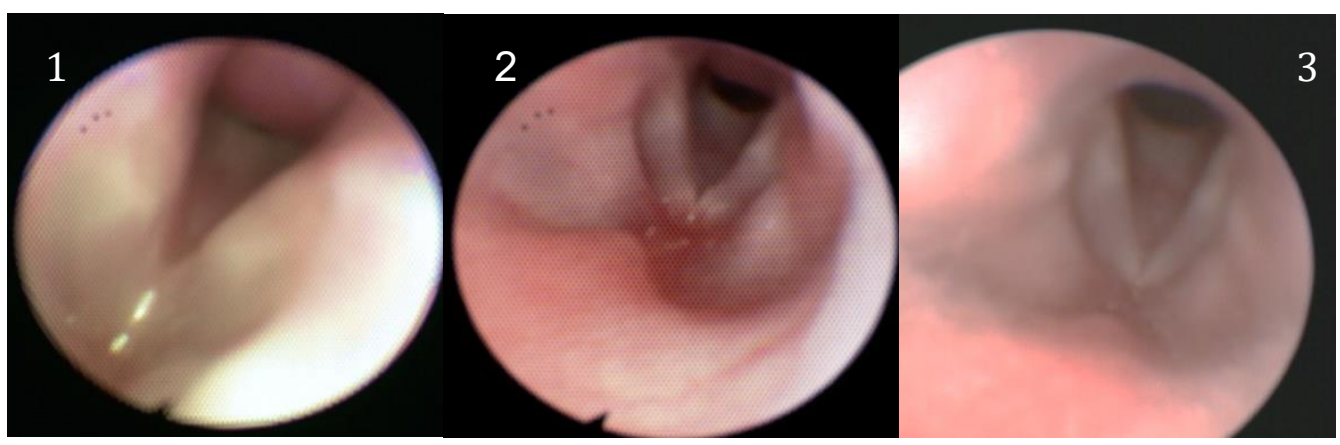

Figura 9. Obstrucción crónica de la vía aérea en la infancia. Hemangioma subglótico. Nuestra experiencia. Tratamiento con propranolol. 1: Antes del inicio del tratamiento, 2: Al mes, 3: a los 7 meses.

\section{ESTENOSIS TRAQUEALES}

La estenosis traqueal es una causa poco frecuente de estridor y distrés respiratorio en pediatría, es importante sospecharla precozmente pues puede comprometer la vida del paciente.

Puede ser congénita o adquirida. La incidencia de las anomalías traqueales congénitas es rara y difícil de determinar, calculándose aproximadamente en un $0,3 \%$ a $1 \%$ de todas las estenosis laringo traqueales [28].

La longitud de la tráquea al nacimiento es generalmente de $3 \mathrm{~cm}$. Se clasifican en estenosis de corto o largo segmento. Se consideran estenosis de largo segmento las que afectan a más de $1 \mathrm{~cm}$ en el recién nacido o las que afectan más del $50 \%$ de la longitud traqueal.

Otra clasificación distingue tres formas anatómicas diferenciadas de estenosis traqueal congénita [29]:

- Forma segmentaria o focal. Se caracteriza por una disminución brusca el diámetro traqueal, en una extensión que no sobrepasa el $40 \%$ a $50 \%$ de la longitud traqueal, localizada básicamente en el tercio medio de la tráquea, y generalmente causada por un engrosamiento de la mucosa respiratoria, en la que se encuentra abundante tejido fibroso.

- Forma en embudo. De localización típicamente supracarinal, suele afectar alrededor del $50 \%$ de la longitud de la tráquea, siendo un extremo más estrecho (el distal), pudiendo o no asociarse a afectación de los bronquios principales.
- Forma difusa. Se caracteriza por un estrechamiento muy marcado de la totalidad de la tráquea, estando ambos árboles bronquiales afectados con mucha frecuencia.

Estas dos últimas formas se caracterizan por la presencia de anillos traqueales completos, es decir, circulares y con agenesia de la «pars membranosa» traqueal.

Aproximadamente el $60 \%$ de los niños con estenosis traqueal congénita tienen otras malformaciones asociadas, particularmente anomalías cardiovasculares [30].

La estenosis traqueal puede ser debida también a compresiones extrínsecas: anomalías cardiovasculares o masas, como quistes o neoplasmas broncogénicos; en otras ocasiones, puede asociarse a atresia esofágica con fístula traqueoesofágica o hendiduras laringotraqueoesofágicas.

Las lesiones adquiridas son generalmente ocasionadas por intubaciones endotraqueales prolongadas o traqueostomas de larga evolución. Otras causas menos frecuentes incluyen complicaciones iatrogénicas resultantes de la endoscopia o intervenciones (láser y dilatación), tumores benignos, traumatismos, lesiones causticas o térmicas, inflamaciones crónicas, enfermedades sistémicas y causas idiopáticas [31].

La clínica va a depender del tipo anatómico, del grado de estenosis y de la presencia o no de anomalías acompañantes y procesos infecciosos sobreañadidos. En el recién nacido puede presentarse como distres respiratorio 
inmediato con imposibilidad para la intubación y elevada mortalidad. Los casos leves pueden pasar inadvertidos durante meses o años hasta que una infección respiratoria sobreañadida precipita una obstrucción respiratoria. El síntoma más frecuente es el estridor mixto o las sibilancias, el distrés respiratorio atípico y las formas atípicas y recurrentes de «croup» y «bronquiolitis» que no ceden con el tratamiento habitual [28-31].

El uso combinado de broncoesofagoscopia flexible y rígida bajo anestesia general con respiración espontánea se considera el método estándar para el diagnóstico. Los estudios de imagen están indicados especialmente en el caso de las compresiones traqueobronquiales extrínsecas debidas a anomalías cardiovasculares [32].

La indicación quirúrgica depende de la presencia de sintomatología respiratoria. El tratamiento debe ser individualizado, según el tipo de lesión, su longitud y las malformaciones asociadas. En pacientes asintomáticos o con síntomas moderados se aconseja seguir una actitud conservadora.

En pacientes con severas comorbilidades o en pacientes con estenosis de tipo simple los procedimientos endoscópicos pueden servir como puente hacia la cirugía, e incluso pueden ser curativos. Consisten en realizar cortes radiales con láser con la ayuda asociada de dilataciones con balón y aplicación de mitomicina. El microdebridador ha demostrado ser efectivo en las lesiones con excesivo tejido de granulación [32, 33].

La cirugía abierta desempeña un papel importante en el tratamiento de las estenosis de tipo compleja y recurrente [31, 34]. En la estenosis de menor longitud, se lleva a cabo la resección quirúrgica del segmento estenótico y anastomosis terminoterminal con buenos resultados, por lo que ha llegado a considerarse el tratamiento de elección. En las estenosis de mayor longitud se ha realizado clásicamente la ampliación de la luz traqueal mediante traqueoplastia con parche de cartílago, o con injerto pericárdico. En la última década estas técnicas se han sustituido por denominada traqueoplastía deslizante [31, 34, 35].

La traqueoplastia deslizante evita el uso de injertos y utiliza el propio tejido traqueal para la reconstrucción (Figura 10). En esta técnica, el segmento estenótico se divide transversalmente en su punto medio, en la mitad superior se realiza una incisión vertical, en su cara posterior y la mitad inferior se secciona en la zona anterior, posteriormente se deslizan juntos y se suturan [36]. Su principal ventaja sobre la traqueoplastia con parche es la inmediata reconstrucción con tejido traqueal nativo, la rápida reepitelización de la herida, la menor tendencia al desarrollo de tejido de granulación y la posibilidad de una rápida y precoz extubación, así como de un adecuado crecimiento traqueal.

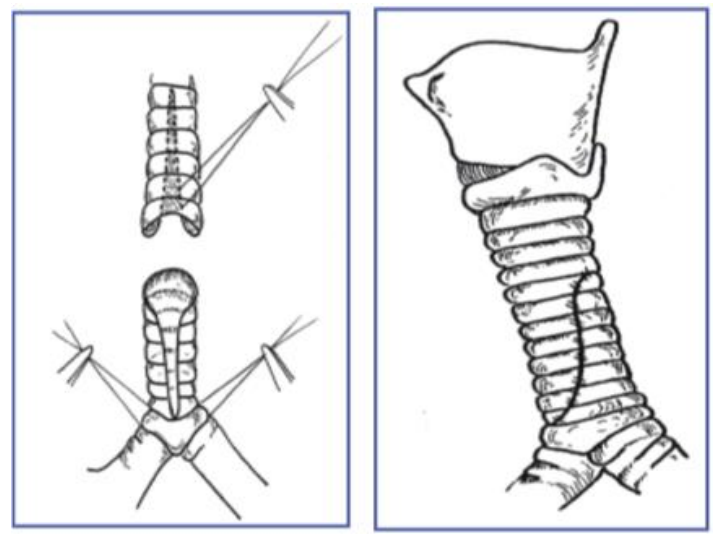

Figura 10. Obstrucción crónica de la vía aérea en la infancia. Traqueoplastia deslizante.

Reproducida de Antón-Pacheco JL. Treatment strategies in the management of severe complications following slide tracheoplasty in children. Eur J Cardiothorac Surg. 2014;46(2):280-5.

Para aquellos pacientes con estenosis complejas que no son susceptibles de tratamiento quirúrgico, o bien esta opción ha fracasado, se recomienda la utilización de tutores [37].

\section{TRAQUEOMALACIA}

La traqueomalacia congénita se define como el debilitamiento de la pared traqueal debido a alteraciones en la maduración de la vía aérea. Su incidencia es aproximadamente 1:2100 niños, y es la anomalía congénita más común de la tráquea [38].

La traqueomalacia puede ser congénita o adquirida y consiste en el colapso de la tráquea durante la respiración. Este colapso ocurre en la mayoría de los casos en la vía aérea intratorácica lo que conduce al estrechamiento de la vía aérea durante la espiración. Puede asociarse a bronquiomalacia [38].

Una de las clasificaciones más utilizadas, define la traqueomalacia primaria cuando afecta a la tráquea en sí misma, en oposición a la traqueomalacia secundaria debida a compresión 
extrínseca (generalmente vascular), fístula o hendiduras esofágicas y cirugía (traqueostomía o reconstrucciones laringotraqueales) [38, 39].

La traqueomalacia primaria se origina por la presencia de una región débil y anormal en un segmento generalmente largo del marco traqueal. Es más frecuente en los bebés prematuros, y puede estar asociada con laringomalacia.

En la mayoría de los casos, los síntomas aparecen antes de los 3 meses. El estridor fundamentalmente espiratorio se acompaña de ataques de cianosis, apneas e infecciones recurrentes de las vías respiratorias. A menudo se producen episodios de apnea y cianosis durante la alimentación, tos y llanto. El bebé frecuentemente asume una posición de hiperextensión cervical del cuello Es característico, por ser un proceso dinámico, la variabilidad tanto en los síntomas como en su intensidad.

Esta condición es generalmente autolimitada, y es posible la recuperación espontánea dentro de los dos primeros años de vida. En lo posible deben evitarse tratamientos agresivos, ya que las complicaciones asociadas a estos pueden ser más problemáticos que la propia enfermedad [38, 39].

La traqueomalacia secundaria se caracteriza, por una debilidad, generalmente localizada, de la tráquea asociada con anomalías mediastínicas, tales como compresiones cardiovasculares extrínsecas, masas (quistes, tumores) o malformaciones esofágicas (atresia esofágica con fistula traqueoesofágica).

Aunque ha habido enormes progresos en los estudios radiológicos, la visualización directa de la vía aérea mediante broncoscopia flexible o rígida sigue siendo el gold standard para el diagnóstico de traqueobroncomalacia. La broncoscopia flexible puede obviar la necesidad de anestesia general y es la modalidad preferida para la visualización directa y evaluación dinámica de la vía aérea [40].

Los casos de traqueomalacia localizada o generalizada leves deben manejarse de manera conservadora con fisioterapia, prevención y tratamiento del reflujo gastroesofágico e infecciones respiratorias [41]. En casos moderados, la presión positiva (CPAP o BiPAP) se suministra a través de una máscara facial durante los períodos de exacerbación.

Los grados más severos requieren intervención. La decisión dependerá de la localización, la presencia de cualquier compresión extrínseca corregible y el pronóstico a largo plazo de la propia condición malácica [41, 42].

Aunque se han descrito otras técnicas quirúrgicas, el tratamiento inicial sigue siendo la aortopexia, descrita por Gross en 1948, cuyos resultados están sobradamente demostrados en la literatura [43, 44].

En casos muy graves, una traqueotomía baja permite la tutorización de la tráquea distal con una cánula larga de traqueotomía. La colocación de una endoprótesis será una opción, cuando las otras modalidades de tratamiento no se consideren adecuadas [37, 45].

\section{HENDIDURAS LARINGOTRAQUEALES}

Se trata de una patología poco común que representan el 0.5 al $1.5 \%$ de las anomalías congénitas laríngeas [46]. Se define como un defecto de la pared entre la vía aérea laringotraqueal y el tracto digestivo superior. Se asocia frecuentemente $(60 \%)$ a anomalías gastrointestinales, genitourinarias, cardiacas 0 craneofaciales.

Se clasifican en cuatro tipos basados en la extensión cráneo-caudal de la hendidura [46, 47]:

- Tipo I: hendidura supraglótica interaritenoidea que se extiende inferiormente a nivel de las cuerdas vocales.

- Tipo II: hendidura parcial cricoidea extendiéndose por debajo del nivel de las cuerdas vocales.

- Tipo III: la hendidura se extiende hasta la tráquea cervical extratorácica.

- Tipo IV: la hendidura se extiende hasta la tráquea intratorácica y ocasionalmente hasta uno de los bronquios principales.

La severidad de los síntomas de relaciona directamente con la extensión de la hendidura. Las hendiduras tipo I a menudo son asintomáticas excepto por algún episodio de aspiración durante la deglución. La aspiración y las neumonías recurrentes con episodios de cianosis o tos durante la deglución son la regla en los casos más severos.

La radiografía de tórax puede mostrar signos no específicos de neumonía por aspiración. En el esofagograma puede demostrarse el paso de contraste dentro de la laringe o tráquea. Esto no es patognomónico pues pude presentarse también en trastornos funcionales de la deglución en caso de laringomalacia, o parálisis de cuerdas vocales. 
El diagnóstico definitivo se realizará mediante endoscopia. La laringoscopia flexible transnasal con respiración espontánea permite descartar laringomalacia, alteraciones de la movilidad de las cuerdas vocales o signos de compresión extrínseca.

La hendidura puede diagnosticarse fácilmente mediante laringotraqueobroncoscopia rígida.

El tratamiento es complejo y depende de la longitud de la hendidura. Las técnicas endoscópicas mínimamente invasivas $[47,48]$ se reservan inicialmente para los casos Tipo I y II. En los casos más graves está indicada la reparación mediante cirugía abierta [47, 49].

\section{SITUACIÓN ACTUAL DE LOS TRATAMIENTOS ENDOSCÓPICOS EN LAS ESTENOSIS LARINGOTRAQUEALES.}

La broncoscopia intervencionista en pediatría ha experimentado un auge importante en las últimas décadas gracias a la experiencia previa en pacientes adultos, el avance en el desarrollo tecnológico y la tendencia a lo mínimamente invasivo. Estas técnicas permiten cirugías con menor dolor y estancia hospitalaria. Muchos de estos procedimientos pueden realizarse sin necesidad de intubación, se pueden realizar en paciente ambulatorio en oposición a la reconstrucción abierta, que puede requerir tratamiento postoperatorio en la $\mathrm{UCI}$ con o sin intubación o ventilación postoperatoria [50].

Las técnicas endoscópicas pueden ser usadas en el tratamiento primario o secundario de las estenosis laringotraqueales. Los tres pilares fundamentales en los que se basan son la laserterapia, las dilataciones y las endoprótesis $[14,33]$.

\section{LASERTERAPIA}

El láser de CO2 tiene poco poder de penetración con poco efecto térmico, lo que minimiza el edema post-procedimiento. Estas características le hacen ideal para el estrecho diámetro de la vía aérea pediátrica [14]. El láser tiene una amplia gama de aplicaciones en las vías respiratorias pediátricas. Es una herramienta útil en el tratamiento de la atresia coanal y papilomatosis respiratoria recurrente, marsupilización de quistes laríngeos, epiglóticos y valleculares [51-55].

La reparación endoscópica de la estenosis glótica, parálisis de cuerdas vocales y estenosis subglótica es exitosa cuando los pacientes son elegidos apropiadamente [14]. Así, la resección primaria con láser está contraindicada en niños con estenosis cartilaginosa congénita dado que la exposición del cartílago en la luz subglótica no se acompaña de repitelización sino a la formación de tejido de granulación. La ablación con láser de las estenosis subglóticas congénitas grado I y II de Cotton y de estenosis subglóticas o traqueales adquiridas membranosas no circunferenciales menores de 1 centímetro ha demostrado ser efectiva [54].

La mayor complicación del tratamiento de las estenosis subglóticas con láser es la reestenosis debida al daño térmico y cicatrización secundaria. En el caso de la recurrencia de la estenosis después de tratamientos endoscópicos primarios debe considerarse la reconstrucción quirúrgica abierta [54].

\section{LARINGOPLASTIA CON BALÓN}

La dilatación, ya sea con balón neumático o con broncoscopios rígidos, ha sido descrita en la literatura con resultados variables.

La dilatación endoscópica efectuada mediante el uso de un balón emplea únicamente fuerzas radiales para reducir al mínimo el daño mecánico en la mucosa, al tiempo que permite un mejor control visual del procedimiento. Está indicada como ayuda a otras técnicas endoscópicas, como la ablación con láser, o de forma aislada ante estenosis simples, cortas, y que no obstruyen por completo la luz de la vía aérea y en los casos de estenosis adquirida de tipo inflamatorio agudo para interrumpir el proceso de formación de cicatrices maduras durante la evolución de la estenosis subglótica $[56,57]$.

\section{ENDOPRÓTESIS}

Las endoprótesis son dispositivos huecos que se colocan en la tráquea o bronquio para mantener la permeabilidad de la luz. Hay una gran experiencia con endoprótesis en la población adulta. El aumento de la experiencia con la colocación endoscópica de prótesis en niños, junto con la disponibilidad de nuevos dispositivos, está favoreciendo su uso en patologías de la vía aérea infantil [37, 45, 58].

\section{Indicaciones:}

- Traqueobroncomalacia: En algunos casos graves la aortopexia y otras técnicas quirúrgicas han fallado o no están indicadas. En este escenario, las únicas alternativas disponibles son una traqueotomía con un tubo 
adecuado o la colocación de una endoprótesis. Queda por definir cuál es el período idóneo de permanencia de la prótesis para disminuir el riesgo de aparición de tejido de granulación, complicaciones a la hora de extraer la prótesis, así como el tipo ideal de prótesis a utilizar.

- Estenosis de las vías respiratorias: La mayoría de las estenosis traqueales en los niños son benignas, congénitas o adquiridas. En pacientes sintomáticos, la traqueoplastia por deslizamiento y la corrección de las anomalías vasculares, cuando están presentes, es el tratamiento de elección.

Aunque algunos autores han recomendado el tratamiento inicial de las estenosis traqueales congénitas y adquiridas con endoprótesis, generalmente este tratamiento se reduce a los casos de complicaciones postquirúrgicas.

En las estenosis complejas esta indicado el tratamiento quirúrgico y las endoprótesis son una ayuda complementaria si el tratamiento faIla o no es factible.

La pérdida de soporte cartilaginoso y la ausencia de compresión extrínseca hacen que las prótesis situadas en la región subglótica o tráquea proximal migren. En estos casos se puede considerar la fijación externa percutánea.

Tipos de endoprótesis:

Las endoprótesis para la vía aérea se clasifican generalmente por el tipo de material del que están fabricadas en [37]:
a) Metálicas
b) Plásticas
c) Hibridas o mixtas
d) Biodegradables

a) Metálicas. Diseñadas en un principio para propósitos endovasculares, actualmente hay una gran variedad de endoprótesis con tamaños disponibles para la vía aérea traqueobronquial infantil (Figura 11). Desde el punto de vista técnico son fáciles de colocar a través del broncoscopio o mediante un tubo endotraqueal dirigido con fluoroscopio. No interfieren con el aclaramiento de moco y es rara la migración. Pueden ser autoexpandibles (Nitinol) o expandibles mediante balón (Palmaz).

b) Plásticas. Las endoprótesis plásticas son generalmente de silicona y son las más utilizadas en el adulto (DUMON), se encuentran disponibles en tamaño pediátrico y se colocan a través del broncoscopio mediante un dispositivo específico. Es importante recordar que las prótesis indicadas para este tipo de lesiones deben ser fácilmente extraíbles, siendo actualmente las de silicona las más utilizados (Figura 12). Tienen una mejor biocompatibilidad que las endoprótesis metálicas, pero menos adherencia por lo que es más frecuente su migración, aunque son más fácilmente extraíbles. Al no ser un material poroso esta alterado el aclaramiento de moco con su posible obstrucción. La experiencia con estas endoprótesis en pediatría es escasa.

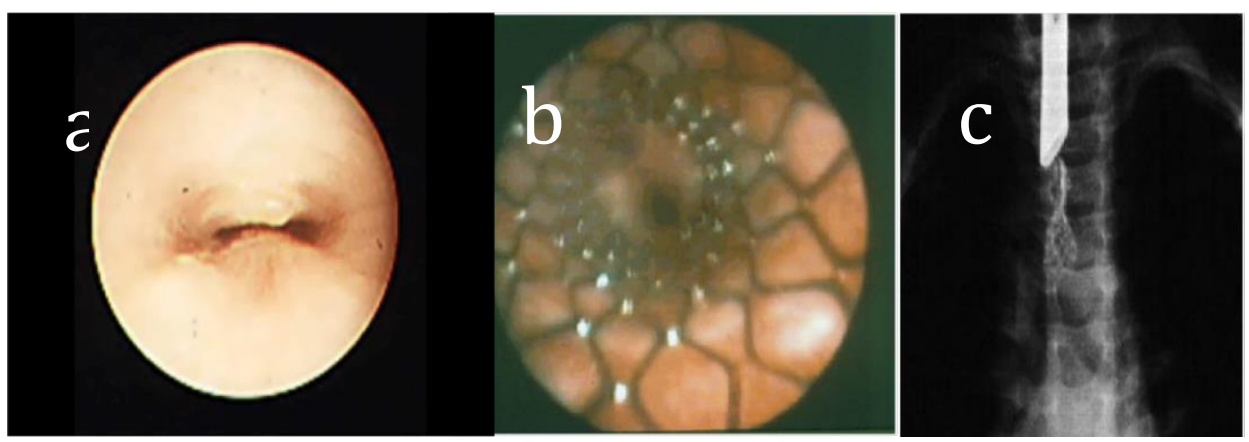

Figura 11. Obstrucción crónica de la vía aérea en la infancia. Endoprótesis metálicas: a: visión endoscópica de la traqueomalacia. b,c :Prótesis metálica tipo Palmaz [37]. 


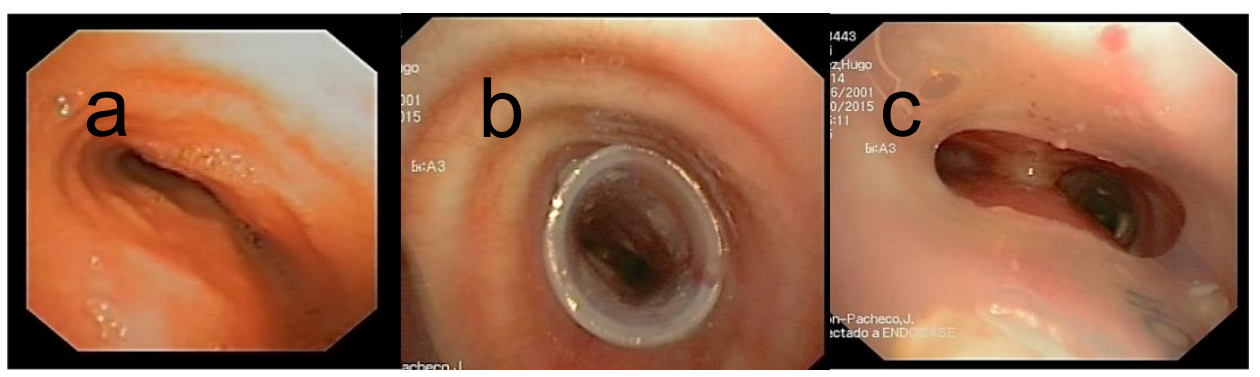

Figura 12. Obstrucción crónica de la vía aérea en la infancia. Endoprótesis plásticas: a: visión endoscópica de la traqueomalacia. b y c: prótesis de silicona tipo DUMON [37, 45].

c) Hibridas. Otra alternativa son las endoprótesis híbridas de nitinol, completamente cubiertas de poliuretano, autoexpandibles y que se pueden retirar, no requieren de la broncoscopia rígida para su colocación. Las endoprótesis híbridas tratan de combinar las ventajas de las metálicas y plásticas, previniendo su mucosalización y facilitando su extracción. Hay poca experiencia en pediatría.

d) Biodegradables (Figura 13). Diseñadas para disminuir las posibles complicaciones de las endoprótesis se han utilizado materiales biodegradables como el monofilamento de polidioxanona (PDS), totalmente reabsorbible, fabricado a medida y autoexpandible que mantiene propiedades biomecánicas 6 a 7 semanas y se degrada por hidrólisis a las 14 o 15 semanas. Existe experiencia previa en esófago, intestino, vía biliar. Se han publicado buenos resultados en traqueobroncomalacia y estenosis traqueales severas difusas [59].

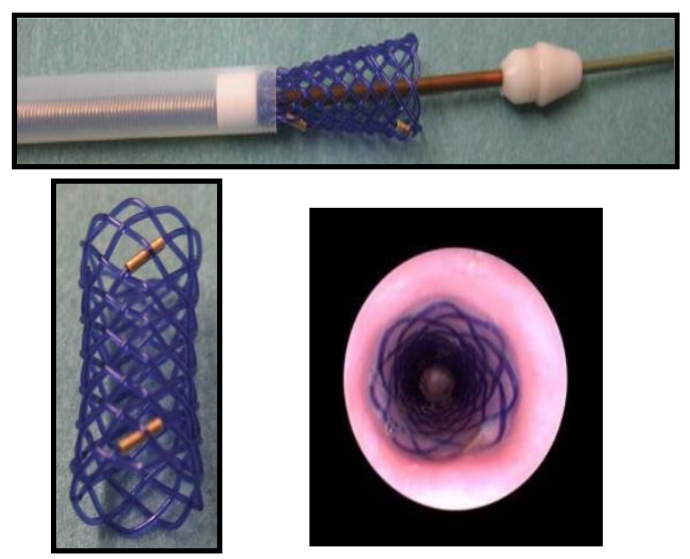

Figura 13. Obstrucción crónica de la vía aérea en la infancia. Prótesis biodegradables [59].

\section{CONCLUSIONES}

Las enfermedades obstructivas que afectan la laringe y tráquea son raras en la infancia.

Una historia clínica detallada es la base para sospechar la presencia de estas anomalías. El signo cardinal es el estridor. Si este es de curso inhabitual (desde los primeros días de vida, presencia de apneas, cianosis, dificultad para alimentarse, dificultad respiratoria, fallo de medro), debe ser derivado para el estudio de su vía aérea.

El abordaje de estas patologías requiere estabilización inmediata, evaluación detallada, planificación meticulosa y tratamiento individualizado. La cirugía de la vía aérea requiere de especialistas organizados en equipos multidisciplinarios cuyo objetivo principal es el diagnóstico y la resolución oportuna de las diversas malformaciones congénitas y lesiones adquiridas que afectan la laringe, tráquea y bronquios.

\section{BIBLIOGRAFÍA}

1. Friedman EM, Vastola AP, McGill TJI, Healy GB. Chronic pediatric stridor: etiology and outcome. Laryngoscope. 1990;100:277-80.

2. Parente Hernández $A$, García-Casillas MA, Matute JA, Cañizo A, Laín A, Fanjul M, et al. ¿Es el estridor un síntoma banal en el lactante? An Pediatr (Barc). 2007; 66(6):55965.

3. Philippe Monnier. Pediatric Ainway Surgery. Management of Laryngotracheal Stenosis in Infants and Children. Springer Heidelberg Dordrecht (London New York) 2011. Endoscopic Assessment of the Compromised Paediatric Airway. p. 77-99.

4. Freitag L1, Ernst A, Unger M, Kovitz K, Marquette $\mathrm{CH}$. A proposed classification system of central airway stenosis. Eur Respir J. 2007; 30(1):7-12. 
5. Monnier $\mathrm{P}$, Dikkers FG, Eckel $\mathrm{H}$, Sittel $\mathrm{C}$, Piazza C, Campos G, et al. Preoperative assessment and classification of benign laryngotracheal stenosis: a consensus paper of the European Laryngological Society. Eur Arch Otorhinolaryngol. 2015;272(10):288596.

6. Goldberg S, Shatz A, Picard E, Wexler I, Schwartz S, Swed E, et al. Endoscopic findings in children with obstructive sleep apnea: effects of age and hypotonia. Pediatr Pulmonol. 2005; 40:205-10.

7. Holinger LD, Konior RJ. Surgical management of severe laryngomalacia. Laryngoscope 1989; 99:136-42.

8. Dedo DD. Pediatric vocal cord paralysis. Laryngoscope. 1979;89:1378-84.

9. Chen, E, Inglis A. Bilateral Vocal Cord Paralysis in Children. Otolaryngol Clin N Am. 2008; 41:889-901.

10. Myer CM, O'Connor DM, Cotton RT. Proposed grading system for subglottic stenosis based on endotracheal tube sizes. Ann Otol Rhinol Laryngol. 1994;103:319-23.

11. Monnier $\mathrm{P}$, Ikonomidis $\mathrm{C}$, Jaquet $\mathrm{Y}$, George $M$. Proposal of a new classification for optimising outcome assessment following partial cricotracheal resections in severe pediatric subglotticstenosis. Int J Pediatrotorhinolaryngol. $\quad$ 2009;73(9):121721.

12. Philippe Monnier. Pediatric Airway Surgery. Management of Laryngotracheal Stenosis in Infants and Children. Preoperative Assessment, Indications for Surgery and Parental Counselling. Springer Heidelberg Dordrecht (London New York) 2011. p. 23140.

13. Antón-Pacheco JL, Canol-García A, Martínez A, Cuadros J, Berchi FL. Patterns of management of congenital tracheal stenosis. J Pediatr Surg.2003; 38:1452-8.

14. Philippe Monnier. Pediatric Ainway Surgery. Management of Laryngotracheal Stenosis in Infants and Children. Endoscopic Techniques for Laryngotracheal Stenosis. Springer Heidelberg Dordrecht (London New York) 2011. p. 241-56.
15. Philippe Monnier. Pediatric Airway Surgery. Management of Laryngotracheal Stenosis in Infants and Children. Laryngotracheoplasty and Laryngotracheal Reconstruction. Springer Heidelberg Dordrecht (London New York) 2011. p. 257-277.

16. Sandu K, Monnier P. Cricotracheal resection. Otolaryngol Clin North Am. 2008;41(5):98198.

17. Philippe Monnier. Pediatric Airway Surgery. Management of Laryngotracheal Stenosis in Infants and Children. Partial Cricotracheal Resection. Springer Heidelberg Dordrecht (London New York) 2011. p. 279-321.

18. Philippe Monnier. Pediatric Airway Surgery. Management of Laryngotracheal Stenosis in Infants and Children. Surgery for Laryngotracheal Stenosis. Springer Heidelberg Dordrecht (London New York) 2011. p. 231-79.

19. Boardman SJ, Albert DM. Single-stage and multistage pediatric laryngotracheal reconstruction. Otolaryngol Clin North Am. 2008;41(5):947-58.

20. Holinger, P.H., Brown, W.T. Congenital webs, cysts, laryngoceles and other anomalies of the larynx. Ann. Otol. Rhinol. Laryngol. 1967;76:744-752.

21. Dyce O, McDonald-McGinn D, Kirschner RE, Zackai E, Young $\mathrm{K}$, Jacobs $\mathbb{I N}$. Otolaryngologic manifestations of the 22q11.2 deletion syndrome. Arch. Otolaryngol. Head Neck Surg. 2002;128:1408-12.

22. Cohen, S.R.: Congenital glottic webs in children. A retrospective review of 51 patients. Ann. Otol. Rhinol. Laryngol. 1985; Suppl.121:2-16.

23. Holinger LD. Congenital laryngeal anomalies. In: Holinger LD, Lusk RP, Green CG (Eds.) Pediatric Laryngology and Bronchoesophagology, Lippincott-Raven, Philadelphia/New York (1997). p. 139-42.

24. Philippe Monnier. Pediatric Airway Surgery. Laryngeal Web and Atresia. Springer Heidelberg Dordrecht (London New York) 2011. p. 125-31. 
25. Broeks IJ, Hermans DJ, Dassel AC, van der Vleuten CJ, van Beynum IM. Propranolol treatment in life-threatening airway hemangiomas: a case series and review of literature. Int J Pediatr Otorhinolaryngol. 2013;77(11):1791-800.

26. Holinger LD, Barnes DR, Smid LJ, Holinger $\mathrm{PH}$. Laryngocele and saccular cysts. Ann. Otol. Rhinol. Laryngol. 1978;87,675-85.

27. Philippe Monnier. Pediatric Airway Surgery. Ductal Cysts, Saccular Cysts and Laryngoceles. Springer Heidelberg Dordrecht (London New York) 2011. p. 141145.

28. Cantrell JR, Guild HG. Congenital stenosis of the trachea. Am J Surg. 1964;108:297-305.

29. Elliott M1, Roebuck D, Noctor C, McLaren C, Hartley B, Mok Q, Dunne C, Pigott N, Patel C, Patel $A$, Wallis $C$. The management of congenital tracheal stenosis. Int $\mathrm{J}$ Pediatr Otorhinolaryngol. 2003; 67:183-92.

30. Herrera $\mathrm{P}$, Caldarone $\mathrm{C}$, Forte V, Campisi $\mathrm{P}$, Holtby $\mathrm{H}$, Chait $\mathrm{P}$, et al. The current state of congenital tracheal stenosis. Pediatr Surg Int. 2007;23(11):1033-44.

31. Backer CL, Mavroudis C, Holinger LD. Repair of congenital tracheal stenosis. Semin Thorac Cardiovasc Surg Pediatr Card Surg Annu. 2002;5:173-86.

32. Anton-Pacheco JL, Cano I, Comas J, Galletti L, Polo L, García A, et al. Management of congenital tracheal stenosis in infancy. Eur J Cardiothorac Surg. 2006;29(6):991-6.

33. Lando T, April MM, Ward RF. Minimally invasive techniques in laryngotracheal reconstruction. Otolaryngol Clin North Am. 2008;41(5):935-46.

34. Backer CL, Mavroudis C, Gerber ME, Holinger LD. Tracheal surgery in children: an 18-year review of four techniques. Eur $\mathrm{J}$ Cardiothorac Surg. 2001;19(6):777-84.

35. Philippe Monnier. Pediatric Airway Surgery. Management of Laryngotracheal Stenosis in Infants and Children. Congenital Tracheal Stenosis. Springer Heidelberg Dordrecht (London New York) 2011. p.167-75.
36. Hewitt RJ, Butler CR, Maughan EF, Elliott MJ. Congenital tracheobronchial stenosis. Semin Pediatr Surg. 2016;25(3):144-9.

37. Antón-Pacheco JL, Cabezalí D, Tejedor R, López M, Luna C, Comas JV, de Miguel E. The role of airway stenting in pediatric tracheobronchial obstruction. Eur $\mathrm{J}$ Cardiothorac Surg. 2008;33(6):1069-75.

38. Kusak B, Cichocka-Jarosz E, JedynakWasowicz U, Lis G. Types of laryngomalacia in children: interrelationship between clinical course and comorbid conditions. Eur Arch Otorhinolaryngol. 2017;274(3):1577-1583.

39. Boogaard R1, Huijsmans SH, Pijnenburg MW, Tiddens HA, de Jongste JC, Merkus PJ. Tracheomalacia and bronchomalacia in children: incidence and patient characteristics. Chest. 2005;128:3391-7.

40. Fraga JC, Jennings RW, Kim PC. Pediatric tracheomalacia. Semin Pediatr Surg. 2016;25(3):156-64.

41. Fayon M, Donato L. Tracheomalacia (TM) or bronchomalacia (BM) in children: conservative or invasive therapy. Arch Pediatr. 2010;17:97-104.

42. De Trey LA, Dudley J, Ismail-Koch $H$, Durward A, Bellsham-Revell H, Blaney S, Hore I, Austin CB, Morrison GA. Treatment of severe tracheobronchomalacia: Ten year experience. Int J Pediatr Otorhinolaryngol. 2016;83:57-62.

43. Jennings RW, Hamilton TE, Smithers CJ, Ngerncham M, Feins N, Foker JE. Surgical approaches to aortopexy for severe tracheomalacia. J Pediatr Surg. 2014;49:6670.

44. Torre M, Carlucci M, Speggiorin S, Elliott MJ, Aortopexy for the treatment of tracheomalacia in children: review of the literature. Ital J Pediatr. 2012;30:38:62.

45. Antón-Pacheco JL. Tracheobronchial stents in children. Semin Pediatr Surg. 2016; 25(3):179-85.

46. Benjamin, B., Inglis, A.: Minor congenital laryngeal clefts: diagnosis and classification. Ann. Otol. Rhinol. Laryngol. 1989; 98:417420.

47. Philippe Monnier. Pediatric Airway Surgery. Laryngeal and Tracheal Clefts. 6. Springer Heidelberg Dordrecht (London New York) 2011. p.147-5. 
48. Rahbar R, Chen JL, Rosen RL, Lowry KC, Simon DM, Perez JA, et al. Endoscopic repair of laryngeal cleft type I and type II: when and why? Laryngoscope 2009;119:1797-802.

49. Simpson BB, Ryan DP, Donahoe PK, Schnitzer JJ, Kim SH, Doody DP. Type IV laryngotracheoesophageal clefts: surgical management for long-term survival. J. Pediatr. Surg.1996; 31:1128-33.

50. Antón-Pacheco JL. Paediatric bronchoscopy: from where we came from, to where we are going. An Pediatr (Barc). 2012; 77(4):223-5.

51. Monnier P, George M, Monod ML, Lang F. The role of the $\mathrm{CO} 2$ laser in the management of laryngotracheal stenosis: a survey of 100 cases. Eur. Arch. Otorhinolaryngol. 2005;262:602-8.

52. Lee KS1, Chen BN, Yang CC, Chen YC. $\mathrm{CO} 2$ laser supraglottoplasty for severe laryngomalacia: a study of symptomatic improvement. Int. J. Pediatr. Otorhinolaryngol. 2007; 71:889-5.

53. Brigger MT, Hartnick CJ. Surgery for pediatric vocal cord paralysis: a meta-analysis. Otolaryngol. Head Neck Surg. 2002;126:34955.
54. Philippe Monnier. Pediatric Airway Surgery. Management of Laryngotracheal Stenosis in Infants and Children. Congenital Subglottic Stenosis..Springer Heidelberg Dordrecht (London New York) 2011. p. 120-124.

55. Wiatrak BJ. Recurrent respiratory papillomatosis. In: Graham JM, Scadding JK, Bull PD. (Eds.) Pediatric ENT, Springer, Berlin Heidelberg (2008). p. 255-65.

56. McArdle J, Gildea T, Mehta A. Balloon bronchoplasty: Its indications, benefits and complications. J Bronchol. 2005;4:123-7.

57. Sharma SD, Gupta SL, Wyatt M, Albert D, Hartley B. Safe balloon sizing for endoscopic dilatation of subglottic stenosis in children. $\mathrm{J}$ Laryngol Otol. 2017;131(3):268-72.

58. Nicolai T. Airway stents in children. Pediatr Pulmonol. 2008;43:330-44.

59. Antón-Pacheco JL, Luna C, García E, López $\mathrm{M}$, Morante R, Tordable $\mathrm{C}$, et al. Initial experience with a new biodegradable airway stent in children: is this the stent we were waiting for? Pediatr Pulmonol. 2016;51(6):607-12. 